\title{
Analyzing Democracy
}

Jeffrey C. Isaac

Perspectives on Politics is a unique political science journal. Approaching its tenth year of existence, its broad mission is to publish excellent political science, and in so doing to contribute to the enlivening of scholarly communication within the discipline and thus to the broader relevance of the discipline in the world. With this in mind, our editorial team decided to "brand" the journal A Political Science Public Sphere. Readers of this journal know that we publish work in a number of formats that mirror the ways that political scientists actually write: self-contained scholarly research articles, more freewheeling and reflective essays, scholarly symposia and critical dialogues, book review essays, and of course the conventional book review.

As the social sciences have developed, professionalized, and perhaps "matured," a premium has increasingly been placed on highly specialized research articles. Perspectives was created in part to foster forms of serious scholarly research and writing that are more broadly accessible within the discipline, and to cultivate what had increasingly become a "lost art" of intellectual conversation and dialogue among scholars separated by subfield, method, and perspective more generally. As a top-tier journal of political science, we accept scholarly research article submissions and publish the very best submissions that make it through our double-blind system of peer review and revision. These articles move through our editorial process individually, in a way that is determined by what authors choose to submit, the timing and recommendations of external reviews, and the unique profiles of individual papers and their authors. The only thing that differentiates Perspectives research articles from other peer-reviewed articles at top journals is that we focus our attention only on work that in some way bridges subfield and methodological divides, and tries to address a broad readership of political scientists about a matter of consequence. This typically means that the excellent articles we publish have been extensively revised in sustained dialogue with the editor-me-to address not simply questions of scholarship but questions of intellectual breadth and readability. At the same time, we also publish other formats that are not subject to double-blind peer review. Everything we publish is carefully vetted and edited. And given our dis- tinctive mission, we work hard to use our range of formats to organize interesting conversations about important issues and events, and to call attention to certain broad themes beyond our profession's normal subfield categories.

Many months ago we made a decision to frame our June 2011 issue around the broad theme of "Analyzing Democracy." Our primary reason for this decision was simple: we had a large number of articles, essays, and symposia in our publication queue that related to this theme, and it seemed wise to run these things together. What we didn't know then was what would happen in Tunisia in December 2010, and how this would spread throughout the region and raise precisely the kinds of broad questions that we had hoped to feature in our journal. In just a few short and fast-paced months, the longruling dictators of Tunisia and Egypt have been deposed by mass movements demanding more democracy; movements voicing similar demands have spread like wildfire throughout the region, posing challenges to ruling elites in Jordan, Yemen, and Bahrain; and as I write this introduction, Libya is being rocked by a protracted conflict that began with civilian demands for the ouster of the dictator and eventuated in said dictator literally making war on his (originally) largely civilian opponents. What political settlements will emerge in these places is highly uncertain, which should be of no great surprise to our readers, who understand that these kinds of political upheavals have diverse and sometimes deep causes; involve popular oppositions and complex elite fractures; domestic, international, and transnational dimensions; and take time to unfold.

Analyzing democracy has long been one of the central preoccupations, and signal contributions, of political science as a discipline. This issue of Perspectives highlights the richness of political science scholarship on this topic. It also highlights the ongoing attentiveness of so many colleagues to issues of deep importance, and the relevance of so much of the work that we do, for almost everything in this issue has been in process for at least a year, long before last December's events. The only exception to this is Marc Lynch's piece, which offers a careful and cautious account of these events and the role of the new social media in promoting them. Marc was in the process of 
revising a different piece, a research article on the Muslim Brotherhood, for resubmission to the journal. When things began to heat up in Egypt, I wrote him to see how his revision was going. He responded by sending me another piece, more directly related to current events, and building on his broader research on the Arab public sphere. I read the piece, shared it with colleagues who validated my sense of its worth, and seized on it. The piece originated in a presentation at last year's APSA conference, but the version that appears here is the product of a single month of extensive and fairly furious revision, the outcome of sustained give and take between author and editor (with major input from two terrific editorial assistants who are also brilliant young scholars of the region, Rebekah Tromble and Hicham Bou Nassif).

Our issue's lead article, John Gerring and Michael Coppedge's "Conceptualizing and Measuring Democracy: A New Approach," builds on the two authors' previous contributions to the political science of democratization and is the product of a more extensive scholarly collaboration. In many ways, this piece is the perfect Perspectives research article - it is tight, it packs a theoretical punch, and it bridges conventional divides between qualitative and quantitative research, and between normative and empirical theory (virtues that were underscored in the unanimous praise of the external reviewers). Gerring and Coppedge proceed from the current lack of consensus about how to conceptualize, measure, and thus compare the "democratic" character of regimes. This dissensus is evident in the diverse systems of coding and scoring employed by Freedom House, Polity, and Bertelsmann, and in the range of measures developed by individual scholars of democratization. As they note, this lack of clear agreement has both theoretical and practical consequences: "Without some way of analyzing regimetypes through time and across countries we have no way to mark progress or regress on this vital matter, to explain it, to reveal its consequences, or to affect its future course." Their article thus carefully surveys and critically evaluates the range of measurement approaches, and then offers an alternative approach that is attentive to the complex meanings of "democracy." In particular, they argue that "democracy" typically comprises at least six distinct dimensionselectoral, liberal, majoritarian, participatory, deliberative, and egalitarian —and that explanatory theories ought to register these distinct dimensions. Gerring and Coppedge describe their approach as "historical, multidimensional, disaggregated, and transparent," and conclude by considering some of the practical obstacles to its application and the ways these might be overcome.

The piece is both theoretical and pragmatic, and this combination is no accident, since Coppedge also chairs the APSA Task Force on Democracy Audits and Government Indicators that was created by President Henry Brady to inventory and assess a variety of conceptualization and measurement issues, and to offer recommendations about the relationships between political science scholars, the APSA, and the range of international institutions and NGOs that draw upon political science research in their work. Brady, one of the original associate editors of this journal, has made a distinguished career of bridging the divides separating qualitative and quantitative methods, and the link between conceptualization and measurement is also the theme of his 2010 APSA Presidential Address, "The Art of Political Science: The Spatial Model as Iconic and Revelatory." A lively address at last year's APSA Conference, the talk, published below, centers on the centrality of spatial metaphors in political inquiry, and on the productive role that visual representations of political space play in illuminating such themes as ideological constraint, cross-pressures, framing, agenda setting, cleavages, political competition, voting systems, party systems, and political polarization. Brady's engaging text is usefully read alongside our wide-ranging Review Symposium on Jon Elster's Alexis de Tocqueville, The First Social Scientist, which also addresses fundamental questions about social science method and the political science of democratization.

As Gerring and Coppedge make clear, consideration of these measurement issues implicates some of the broadest theoretical questions relating to democracy and democratization. This is also made clear in the discussions of the Task Force published in the February 2011 Comparative Democratization, the newsletter of the APSA Comparative Democratization section, and in particular Gerardo L. Munck's introduction to those discussions, "Measuring Democracy: Framing a Needed Debate." In recent years, Munck has been an important contributor to these discussions, and it is fitting that his book Measuring Democracy: A Bridge between Scholarship and Politics is reviewed by Henry Hale below. This issue also contains a book review essay by Munck, "Democratic Theory after Transitions from Authoritarian Rule." Reviewing recently published books on democratization by Guillermo O'Donnell, Adam Przeworski, and Alfred Stepan and Juan Linz, Munck also reflects broadly on the distinctive approach to democratization that they helped to pioneer over thirty years ago through their participation in the important Woodrow Wilson Center project on "Transitions from Authoritarian Rule." As Munck notes, the project culminated in the publication of the four-volume Transitions from Authoritarian Rule, which set the terms of subsequent scholarly discussion among "transitologists" interested in the "third wave" of democratic transformation. Munck's review essay assesses the accomplishments and limits of this research agenda over the past thirty years and proceeds to discuss the ways O'Donnell, Przeworksi, and Stepan and Linz have recently deepened this agenda, the former two through their attention to broader issues of conceptualization, and the latter two through their attention to questions of political identity and especially the complex relationships between nation, state, and democracy. 
Laurence Whitehead was an important participant in the Wilson Center project, coediting and contributing to a number of the volumes mentioned above. And so I am especially pleased to note his Reflections essay, "Enlivening the Concept of Democratization: The Biological Metaphor." Like the books by O'Donnell and Przeworski reviewed by Munck, and consistent with the "multidimensional" approach of Gerring and Coppedge, Whitehead's piece seeks to deepen the conceptualization of democracy. As he writes, "This essay focuses on processes of democratization, rather than on the ideal of democracy as a single fixed and internally consistent end-state, and asks whether biology provides better analogies than mechanics for reasoning about contemporary democratization processes." Whitehead is alive to both the strengths and the limits of employing biological metaphors in political science. At the same time, he makes a very strong case that certain biological metaphors-especially "contagion," "viability," and "hybridity" - offer essential insight into the processes by which democracy evolves, consolidates, spreads, and is forestalled.

If one feature of recent scholarship on democracy is a greater attentiveness to questions of conceptualization, dimensionality, and "quality," a second is attentiveness to the contingencies and limits of democratization and, even more important, to the bona fide characteristics of nondemocratic regimes, which are, arguably, sui generis and not simply anomalies of incomplete "democratization."

Baogang He and Mark E. Warren's "Authoritarian Deliberation: The Deliberative Turn in Chinese Political Development" is a terrific contribution to this discussion. Like the Gerring and Coppedge piece, it combines normative and empirical analysis; a self-styled work of "comparative political theory," it speaks broadly to questions at the heart of comparative politics, offering a conceptualization of "deliberative authoritarianism" that is grounded in the Chinese case but has potentially broader relevance. As $\mathrm{He}$ and Warren explain,

Over the last two decades, authoritarian regimes in Asia have increasingly experimented with controlled forms of political participation and deliberation, producing a variety of "hybrid" regimes. These regimes mix authoritarian rule with political devices including elections, consultative forums, political parties, and legislatures that we would normally associate with democracy. China is a particularly important case: though it remains an authoritarian country led by the Chinese Communist Party (CCP), its government is now permeated with a wide variety of participatory and deliberative practices.... While very uneven in scope and effectiveness, many of these innovations appear to have genuinely deliberative elements, from which political leaders take guidance, and upon which they rely for the legitimacy of their decisions. Typically, however, deliberation is limited in scope and focused on particular problems of governance. Curiously, these practices are appearing within an authoritarian regime led by a party with no apparent interest in regime-level democratization.
He and Warren insist that this deliberative authoritarianism is "normatively ambiguous." At the same time, drawing on the work of Andrew Nathan, they leave no doubt that the deliberative mechanisms on which they focus contribute to the "resilience" of Chinese authoritarianism.

Resilience is also the theme of Marc Lynch's Reflections essay, "After Egypt: The Limits and Promise of Online Challenges to the Authoritarian Arab State." Writing in the wake of Hosni Mubarak's fall from power in Egypt, Lynch notes that the recent uprisings in the Arab world have "destabilized the findings of a sophisticated literature on authoritarian persistence which had developed over the previous decade to explain the resilience of Arab authoritarian states in the face of multiple disruptive forces." Lynch argues that the dramatic upheavals currently underway require a "broad rethinking of this literature." In particular, they highlight the importance of the role of new social media in "reducing transaction costs for organization and presenting rapid and powerful channels for the dissemination of messages, images, and frames," at the domestic, regional, and global levels. At the same time, Lynch argues that these new media are a double-edged sword. While they enhance certain kinds of protest, they do not necessarily promote "enduring movements or ... robust political parties capable of mounting a sustained challenge to entrenched regimes." Indeed, "these same tools can strengthen the surveillance and repression capabilities of authoritarian states." Lynch thus concludes on a jaundiced note, acknowledging the potential of recent events, but also maintaining that in the end, they may "reaffirm the existing arguments about authoritarian resilience, if the upheavals result in newly configured but fundamentally similar military regimes."

The first of our critical dialogues, placing Steven Levitsky and Lucan Way into conversation with Dan Slater, centers broadly on the underlying sources of authoritarian power and resilience. Levitsky and Way have long been important contributors to debates in comparative politics about "hybrid regimes," and their new book, Competitive Authoritarianism: Hybrid Regimes after the Cold War, seeks to explain the means by which authoritarian regimes in the post Cold War world have sought to incorporate elections and other forms of contestation within a generally antidemocratic framework, as a way of sustaining authoritarian power. Levitsky and Way provide both a conceptualization of a regime-type- "competitive authoritarianism" - and a theory seeking to explain variation in the extent to which such regimes can develop relatively stable structures of rule or alternatively be liable to tendencies toward democratization. Dan Slater's Ordering Power: Contentious Politics and Authoritarian Leviathans in Southeast Asia is an equally ambitious book, if more limited in the scope of its comparisons. Slater's book offers a self-styled "Hobbesian" account of the conditions under which rulers can successfully develop 
"protection pacts" with social elites. As he writes, "the most durable dictatorships do not rest on delivering patronage or coddling the wealthy, but on a history of 'ordering power': extracting and organizing political, economic, and symbolic resources from a wide array of elites." In their critical dialogue, the authors raise and briefly debate a number of important theoretical questions, about the international versus the domestic sources of authoritarian stability and instability, the relative importance of macroand microlevels of analysis, and the historical specificity of certain mechanisms and regime types. Their dialogue makes clear that cutting-edge political scientists can acknowledge similar problems - the persistence of authoritarianism and particularly its hybrid forms - and offer broadly similar approaches, and at the same time disagree about some very important things. It also makes clear that such disagreements, when enacted with intellectual seriousness and collegial respect, are profoundly constructive, and indeed are at the heart of scientific inquiry.

Mike McGovern's review essay, "Popular Development Economics-An Anthropologist among the Mandarins," also addresses the weaknesses of a teleological approach to democratization and modernization. McGovern reviews two books by the prominent economist Paul CollierThe Bottom Billion: Why the Poorest Countries Are Failing and What Can Be Done about It and Wars, Guns, and Votes: Democracy in Dangerous Places. But McGovern treats this review as an occasion to raise a set of broader questions about Collier's "attempts to bring African and other poor countries with problems of 'stuck' development back into the conversation of economists, policymakers, and an educated nonspecialist readership." McGovern is an anthropologist, and his sharp and beautifully written essay centers on the tension between the disposition of most anthropologists to seek "thick description" and the disposition of most professional economists to seek parsimonious models that travel easily from one situation to the next. McGovern makes clear that this dualism is unfortunate, and indeed he draws on the work of political scientists Stathis Kalyvas, Jim Scott, and Elizabeth Wood to sketch a more nuanced synthesis of grounded understanding and theoretical generality. McGovern appreciates Collier's serious engagement with real problems in real contexts. At the same time, he argues that in too many respects, Collier's economic analyses proceed from simplistic assumptions that are ungrounded in contextual knowledge. His critique of Collier is methodological, but it is also political. As he writes, "Despite the adoption of a Naipaulian unsentimental-dispatches-fromthe-trenches rhetoric, the story told in Collier's two books is in the end a morality tale. The tale is about those countries and individuals with the gumption to pull themselves up by their bootstraps or the courage to speak truth to power, and those power-drunk bottom billion elites, toadying sycophants, and soft-hearted academics too blinded by misplaced utopian dreams to recognize the real causes of economic stagnation and civil war." McGovern insists that social science must explain the persistence of poverty, war, and authoritarianism, enduring and rooted features of our social landscape hardly fated to disappear. At the same time, he insists on the complexity of local situations, the agency of ordinary people, and the contingency of political outcomes-and thus the ever-present possibility of change.

This liability of even the most apparently settled power relations to democratic contestation is, of course, a major lesson of recent events in the Middle East, and it is a theme of many of the books reviewed in this issue's special review section, "Analyzing Democracy." It is also one of the important themes taken up in our critical dialogue between Deborah Gould and Rafael de la Dehesa, authors of two books about social movement activism, rights claims, and the politics of empowerment. Gould's book Moving Politics: Emotion and ACT UP's Fight Against AIDS is an account of direct-action AIDS activism in the United States from its emergence in the mid-1980s through its decline in the early 1990s. De la Dehesa's Queering the Public Sphere in Mexico and Brazil: Sexual Rights Movements in Emerging Democracies takes up similar themes in a more comparative vein. Both books analyze the repertoires of contentious politics employed by social movements acting in the name of excluded and marginalized groups, and the dialogue between the authors highlights both the tensions and the complementarities between an approach centered on "affect" and one more attuned to questions of "political opportunity structure."

In his critical response to Gould, de la Dehesa comments on the "tension ... between a contentious, directaction activism, fueled primarily by anger, and an activism that operates through established political institutions." This tension is a major theme of political science scholarship on the politics of democratization, and it is also a profound practical challenge faced by activists and citizens in places ranging from Egypt and Libya to China and Mexico to Madison, Wisconsin, who confront political systems, and policy regimes, that embody both opportunities but also obstacles, and who must figure out how best to act politically under conditions of uncertainty.

In referencing Madison, Wisconsin, I mean to bring this introduction full circle by calling attention to the labor struggles currently taking place in Wisconsin, Ohio, and my own state of Indiana, which can perhaps be seen as "demonstration effects" of what is happening in the Middle East. For as we know, "democracy" is not simply a question "over there." It is a problem everywhere, including here. In future issues of Perspectives, we will focus some attention on problems of democratic inclusion closer to "home," by highlighting the theme of immigration rights, and in a symposium on Jacob Hacker and Paul Pierson's new book Winner-Take-All Politics: How Washington 
Made the Rich Richer-and Turned Its Back on the Middle Class. While it is tempting to structure the study of US politics around such conventional themes as "Congress," "parties," and "public opinion," in fact the same sorts of broad institutional questions about power, movement, and institutionalization that structure the comparative study of democratization arise in the United States as well. J. Mitchell Pickerill's review essay, "Law, Politics, and Democracy in the Twenty-first Century," makes this clear. Pickerill discusses three important new books on US "judicial politics" that together highlight the complex relationships between "juridification," litigation, and the politicization of fundamental rights claims (a theme also developed in the terrific book reviews by Jan-Werner Müller and Jacob T. Levy). Indeed, as most of the articles and essays in this issue of Perspectives underscore, the analysis of "democracy" knows no geographical or methodological bounds. Wherever there are states, citizens, and relations of power, "democracy" is in question. And wherever democracy is in question, the rich and diverse modes of inquiry that comprise political science have an important role to play in illuminating what $\mathrm{C}$. Wright Mills long ago called "the present as history and the future as responsibility." 


\section{Statement of Mission and Procedures}

Perspectives on Politics seeks to provide a space for broad and synthetic discussion within the political science profession and between the profession and the broader scholarly and reading publics. Such discussion necessarily draws on and contributes to the scholarship published in the more specialized journals that dominate our discipline. At the same time, Perspectives seeks to promote a complementary form of broad public discussion and synergistic understanding within the profession that is essential to advancing scholarship and promoting academic community.

Perspectives seeks to nurture a political science public sphere, publicizing important scholarly topics, ideas, and innovations, linking scholarly authors and readers, and promoting broad reflexive discussion among political scientists about the work that we do and why this work matters.

Perspectives publishes work in a number of formats that mirror the ways that political scientists actually write:

Research articles: As a top-tier journal of political science, Perspectives accepts scholarly research article submissions and publishes the very best submissions that make it through our double-blind system of peer review and revision. The only thing that differentiates Perspectives research articles from other peer-reviewed articles at top journals is that we focus our attention only on work that in some way bridges subfield and methodological divides, and tries to address a broad readership of political scientists about matters of consequence. This typically means that the excellent articles we publish have been extensively revised in sustained dialogue with the editor-me- to address not simply questions of scholarship but questions of intellectual breadth and readability.

"Reflections" are more reflexive, provocative, or programmatic essays that address important political science questions in interesting ways but are not necessarily as systematic and focused as research articles. These essays often originate as research article submissions, though sometimes they derive from proposals developed in consultation with the editor in chief. Unlike research articles, these essays are not evaluated according to a strict, doubleblind peer review process. But they are typically vetted informally with editorial board members or other colleagues, and they are always subjected to critical assessment and careful line-editing by the editor and editorial staff.

Scholarly symposia, critical book dialogues, book review essays, and conventional book reviews are developed and commissioned by the editor in chief, based on authorial queries and ideas, editorial board suggestions, and staff conversations.

Everything published in Perspectives is carefully vetted and edited. Given our distinctive mission, we work hard to use our range of formats to organize interesting conversations about important issues and events, and to call attention to certain broad themes beyond our profession's normal subfield categories.

For further details on writing formats and submission guidelines, see our website at http://www.apsanet.org/ perspectives/ 